\title{
Molecular evaluation of Hepatocyte Growth Factor (HGF) as a potential Biomarker to detect Hepatocellular Carcinoma
}

\author{
Amira Abdallah $^{1}{ }^{*}$, Moustafa A. Sakr ${ }^{1}$, Ahmed Sharawy ${ }^{2}$, Hisham A. Ismai1 ${ }^{1}$ \\ ${ }^{1}$ Molecular diagnostics and therapeutics department, Genetic Engineering and \\ Biotechnology Research Institute (GEBRI), University of Sadat City, Egypt \\ ${ }^{2}$ Clinical Pathology Department, National Liver Institute, Menofia University
}

Corresponding author: Amira Abdallah Email:amoo201121@yahoo.com

\begin{abstract}
This study was carried out to investigate the noninvasive expression level of hepatocyte growth factor (HGF) in hepatocellular carcinoma patients and its relationship with diagnostic parameters. To active this goal we used thirty six patient divide to fourteen with HCC, twelve patients with HCV and ten healthy control patient matched in age and sex were investigated. HGF level wasdetected by quantitative polymerase chain reaction (qRT-PCR). The median age of the patients was 51 years (rang 44-58 years); where males constituted the majority of the group (69.4\%). The entire patient had cirrhotic history. None of the patients were pretreated with local therapies. The baseline noninvasive HGF level wassignificantly higher in patient HCC than in the HCV and control groups $(\mathrm{p}=0.028)$, whereas HGF level was alsohigher in HCV patient than healthy patient. Further the correlation between the level of HGF and all laboratory parameters was tested. We found that there is a good positive relationship between HGF levels and SGPT (ALT), SOGT (AST), Platelets count.Finally we compared the predicative accuracy of HGF and a conventional tumor marker AFP by ROC curve; we found that the sensitivity of HGF $(85.7 \%)$ to predict the HCC is higher than AFP (73\%), and also the specificity.Overall, these results suggest that HGF could serve as a useful tumor biomarker for prediction of HCC in comparing with, $\mathrm{HCV}$, and healthy control results.
\end{abstract}

Key words: $H C C, H G F, A F P, R O C$ curve, Egyptian patients

\section{INTRODUCTION}

The hepatitis $\mathrm{C}$ virus (HCV) forms the genus Hepacivirus within the Flaviviridaefamily. $\mathrm{HCV}$ is a positivestrand RNA virus encoding a single polyprotein precursor (Simmonds, 2013), that is generated by RNA translation at the rough endoplasmic reticulum (ER). This polyprotein is proteolytically processed into 10 mature proteins in a preferential, but not obligatory order (Niepmann, 2013; Moradpour and Penin, 2013). HCV replicates in the cytoplasm of hepatocytes, but is not directly cytopathic. Persistent infection appears to rely on rapid production of virus and continuous cell-tocell spread, along with a lack of vigorous Tcell immune response to $\mathrm{HCV}$ antigens. The HCV turnover rate can be quite high with replication ranging between $10^{10}$ to
$10^{12}$ virions per day, and a predicted viral half-life of 2 to 3 hours (Neumann, 1998). The rapid viral replication and lack of error proofreading by the viral RNA polymerase are reasons why the HCV RNA genome mutates frequently(Bukh et al,. 1995). Althoughvariants of HCV show substantial genetic diversity from each other, the 7 currentlyclassified genotypes are all classified as one species un notwithstanding their considerably antigenic variability and geographicaldifferences distribution(Simmonds et al,. 2011). Chronic HCV infection significantly increases the risk of liver cirrhosis and hepatocellular carcinoma (Hoofnagle, 2002).

Hepatocellular carcinoma ranks sixth in incidence and third in mortality among all cancers worldwide (Ferlay et al,. 2008), 
accounts for $70-85 \%$ of case (Perz et al,. 2006). Major etiological risk factors for HCC include HCV,HBV, alcoholic liver disease, and nonalcoholic fatty liver disease. These risk factors lead to the formation and progression of cirrhosis, which is present in about $80-90 \%$ of $\mathrm{HCC}$ patients. The 5-year cumulative risk of developing HCC in patients with cirrhosis ranges between $5 \%$ and $30 \%$ depending on etiology (highest in $\mathrm{HCV}$ ), region or ethnicity (highest in Asians), and stage of cirrhosis (highest in decompensated disease) (Fattovich et al. 2004).We recommend a combination of liver ultrasound and serum alpha fetoprotein (AFP). Liver ultrasound is recommended as the primary surveillance modality for $\mathrm{HCC}$; it has a modest sensitivity of approximately $60 \%$ and a higher specificity of nearly $85-$ 90\% (Singal et al. 2009). Computed axial tomography (CT) and magnetic resonance imaging (MRI) scans have not been adequately tested for HCC surveillance, but are used in clinical practice. CT and MRI are associated with increased detection ofHCC than ultrasound but they are also associated with a higher false-positive rate (Kobayashi et al. 1985) AFP measurement is commonly used for HCC surveillance because it is relatively inexpensive, simple to perform, and is widely available. AFP alone (without liver ultrasound) is not recommended as a HCC surveillance test due to its low sensitivity and specificity for detecting HCC. At a serum cutoff level of $20 \mathrm{ng} / \mathrm{ml}$, AFP has low sensitivity ranging from $25 \%$ to $65 \%$ for detecting HCC (Paul et al. 2007).Although several advanced treatments are now available, including surgical resection, liver transplantation and ablation therapies (Belghiti and Fuks, 2012), and in spite of the development of molecular-target drugs such as sorafenib(Palmer, 2008), the five-year overall survival rate of patients with advanced HCC remains poor (Kishiet al,. 2011). The main reason for the poor survival rate of advanced HCC is the high rate of recurrence and metastasis after local treatment (Ueno et al,. 2011).

Hepatocyte growth factor/scatter factor $(\mathrm{HGF} / \mathrm{SF})$ is apleiotropic growth factor originally isolated from rat platelets. HGF- like factor known as macrophage/simulating protein (MSP) is an $82 \mathrm{kDa}, 674$ amino acid residue heterodimeric glycoprotein that is part of a small family of factors (Nakamura 1994). HGF which is mainly secreted by Kuppfer cells, endothelial cells, fibroblasts and hepatic stellate cells in the liver, has been shown to have a role in embryonic organ development, adult organ regeneration and wound healing (Nakamura, 1991). Secretion by stellate cells and myofibroblasts is apparently induced by tumor cell signals; HGF, in turn, stimulates tumor cell invasiveness (Neaud et al., 1997; Guirouilh et al., 2001). HGF signaling drives the transcriptional activation of MET in HCC (Seol et al., 2000), and HGF is over expressed in the HCC microenvironment relative to normal adult liver levels (Selden et al., 1994; Noguchi et al., 1996). The aim of this casecontrol study is to investigate the expression level of HGF in HCC Egyptian patients by noninvasive technique and the potentiality of predicting HCC patients.

\section{PATIENTS AND METHODS}

\section{Patient}

This study included 36 patients (25 male and 11 female) cases. Their ages ranged from 44 to 58 years. They were performed on individuals referred to National Liver Institute Hospital, Menofiya University, Egypt, for chronic liver diseases. The patients were selected all over a period of 6 months from the outpatient clinics and inpatient during period from $15^{\text {th }}$ December 2014 to $28^{\text {th }}$ October 2015. Ofthese, 10 healthy control patient $(27.8 \%)$ were $5(50.0 \%)$ male and $5(50.0 \%)$ female ages ranged from 44 to 55 years old (mean age, 48.20 years).

All of the patients were have positive of serum hepatitis $\mathrm{C}$ virus identified by serology and confirmed by qualitative PCR 
to detect HCV-RNA. They had focal lesion that were detected by ultrasonography and computed tomography (CT) scan. All patients were negative serum hepatitis B surface antigen (ELISA). Blood samples were obtained only from patients who gave informed consent.A full history was taken from all patients and control. Exclusion criteria included: patients with chronic HBV infection or any other known cause for chronic hepatitis other than HCV, previous treatment for $\mathrm{HCC}$ or antiviral therapy and any associated malignancies other than HCC.

Peripheral blood samples were collected for routine workup, including complete blood count, liver function tests, and prothrombin time, AFP, anti-HCV titer, $\mathrm{HBs} \mathrm{Ag}$, and $\mathrm{HBc}-\mathrm{Ab}$ using commercial assays.

\section{qRT-PCR for HGF}

Blood semples of the HCC, HCV and control groups were obtained by veinpuncture with EDTA as anticoagulant. The whol blood collected following frozen immediately at $-80^{\circ} \mathrm{CUntil}$ analyzed for HGF.

The HGF RT-PCR (real time polymerase chain reaction) is a technique in molecular genetics that permits the analysis of any short sequence of RNA even in samples containing only minute quantities of RNA. RNA isolation from whole blood wasdone by PureLink RNA mini kit (thermos scientific. USA) according to the manufacture instructions. The cDNA Synthesis is designed for the sensitive and high yields synthesis and analysis of full-length cDNA copies from either a total or poly(A)+ RNA sample. They optimized for a Reverse Transcription (RT ase) reaction that can utilize any amount of total RNA from $1 \mathrm{pg}$ to $5 \mu \mathrm{g}$ per reaction and is application and is applicable for the synthesis of full-length first strand cDNA. Real-time PCR reaction with intercalating dye( Syber green dye) This is a $2 X$ concentration premix type reagents, which contains all reagents for real-time
PCR reaction except for primers. This makes preparation of reaction mixture easer. Intercalating dye in the master mix enables the analysis of many different targets without having to synthesize targetspecific labeled probes. The results of HGF were expressed as fold change.

\section{Statistical analysis}

Data were analyzed with Statistical Package for the Social Sciences (SPSS version 20.0) (Statistical Package for the Social Sciences). According to the type of data qualitative represent as number and percentage, quantitative continues group represent by mean $\pm \mathrm{SD}$, the following tests were used to test differences for significance; Differences between frequencies (qualitative variables) and percentages in groups were compared by Chi-square test. Differences between parametric quantitative independent multiple groups by ANOVA non parametric by Krusskle Wallace.ROC curve for cut off, Kappa agreement to test the agreement non parametric correlation by Spearman's correlation. $\mathrm{P}$ value was set at $<0.05$ for significant results $\&<0.001$ for high significant result.

\section{RESULTS}

Demographic data, biochemical, and hematological characteristics of the studied groups

The values of the demographic, hematological, and biochemical variables of the groups under study are summarized in Table (1). The median ages of healthy control, HCV, and $\mathrm{HCC}$ patients were (48.2, 51.4,47.58.2) years respectively.Gender was not significantly different between HCV, and HCC groups. Serum levels of ALT (SGPT), AST (SGOT), total bilirubin, and INRwere significantly higher in HCC than other groups; whereas albumin, hemoglobin levels, and platelets count were significantly lower in HCC patients versus the other groups. TotalWBCs count and creatininewere not significantly different between studied groups. 
Table 1.Demographic data, biochemical, and hematological characteristics of the studied groups

\begin{tabular}{|c|c|c|c|c|}
\hline \multirow[b]{2}{*}{ Variables } & \multicolumn{3}{|c|}{ Mean \pm SD } & \multirow[b]{2}{*}{ P value } \\
\hline & $\begin{array}{c}\text { Control } \\
(n=10)\end{array}$ & HCV $(n=12)$ & HCC $(n=14)$ & \\
\hline \multicolumn{5}{|l|}{ Demographic Data } \\
\hline Age: Range (Mean) & $44-55(48.2)$ & $47-55(51.4)$ & $47-58(53.4)$ & NS \\
\hline \multicolumn{5}{|l|}{ Gender } \\
\hline Male & $5(50 \%)$ & $10(83 \%)$ & $10(71 \%)$ & NS \\
\hline Female & $5(50 \%)$ & $2(17 \%)$ & $2(19 \%)$ & \\
\hline \multicolumn{5}{|l|}{$\begin{array}{l}\text { Biochemical } \\
\text { parameters }\end{array}$} \\
\hline ALT (up to $40 \mathrm{U} / \mathrm{L}$ ) & $(20.3 \pm 7.3)^{1}$ & $(43 \pm 11.8)^{2}$ & $(48.57 \pm 23.7)^{2}$ & $0.001 * *$ \\
\hline SGOT (up to $50 \mathrm{U} / \mathrm{L}$ ) & $(19.7 \pm 5.3)^{1}$ & $(37.08 \pm 8.3)^{1}$ & $(50.85 \pm 26.6)^{2}$ & $0.001 * *$ \\
\hline Total Bil. $(\sim 1 \mathrm{mg} / \mathrm{dL})$ & $(.63 \pm .094)^{1}$ & $(.6833 \pm .071)^{1}$ & $(1.00 \pm .34)^{2}$ & $0.00 * *$ \\
\hline $\begin{array}{l}\text { Albumin }(3.5: 5.5 \\
\mathrm{gm} / \mathrm{dL})\end{array}$ & $(3.9 \pm .161)^{1}$ & $(3.75 \pm .137)^{1}$ & $(3.23 \pm .617)^{2}$ & $0.00 * *$ \\
\hline Glucose & $(81.3 \pm 14.74)^{1}$ & $(80.58 \pm 6.55)^{1}$ & $(104.85 \pm 37.10)^{2}$ & $0.028 *$ \\
\hline Creatinine & $(.6930 \pm .14)^{1}$ & $(.75 \pm .10)^{1}$ & $(.9121 \pm .39)^{2}$ & 0.118 \\
\hline \multicolumn{5}{|l|}{$\begin{array}{l}\text { Hematological } \\
\text { parameters }\end{array}$} \\
\hline $\begin{array}{l}\text { Plat.(150:450x } 10^{3} / \\
\left.\mathrm{mm}^{3}\right)\end{array}$ & $(322.6 \pm 66.42)^{1}$ & $(237 \pm 31.5)^{1}$ & $(125.5 \pm 43.27)^{3}$ & $0.00^{* *}$ \\
\hline Prothrombin time & $(11.81 \pm 0.64)^{1}$ & $(12.28 \pm 0.1) 1$ & $(13.41 \pm 1.2)$ & $0.003^{*}$ \\
\hline $\begin{array}{l}\text { Prothrombin } \\
\text { concentration }\end{array}$ & $(91.0 \pm 8.7)^{1}$ & $(88.83 \pm 10.3) 1$ & $(77.49 \pm 12.4)$ & $0.008^{*}$ \\
\hline INR & $(1.06 \pm 0.07)^{1}$ & $(1.133 \pm 0.12)^{1}$ & $(1.186 \pm 0.109)^{2}$ & $0.033^{*}$ \\
\hline WBCs $\left(3.9: 11 \times 10^{3} / \mathrm{mm}^{3}\right)$ & $(4.40 \pm 0.3)^{1}$ & $(4.4667 \pm 0.27)^{1}$ & $(3.9143 \pm 0.71)^{2}$ & $0.015^{*}$ \\
\hline RBCs & $(4.6700 \pm 0.3)^{1}$ & $(4.4667 \pm 0.27)^{1}$ & $(5.00 \pm 2.38)^{2}$ & 0.674 \\
\hline $\mathrm{Hgb}(11.5: 16.5 \mathrm{gm} / \mathrm{dL})$ & $(12.73 \pm 0.87)^{1}$ & $(13.58 \pm 0.59)^{1}$ & $(11.92 \pm 1.56)^{2}$ & $0.003^{*}$ \\
\hline
\end{tabular}

Groups bearing different numbers are significantly different from each other at $\mathrm{P}<0.05$

* show statistical significant difference

AFB and HGF levels and their correlation with the laboratory findings in $\mathrm{HCC}$

As shown in Table 2, and Figure 1 the level of the HGF detected from the whole blood by noninvasive technique and tested by qRT-PCR in HCC cases and other groups normalized GAPDH as internal control.We found that the expression level of HGF was significantly higher in chronic hepatitis $\mathrm{C}$ and $\mathrm{HCC}$ in comparing of healthy control group $(p=0.046)$. Whereasthe median level

of serum AFP showed a significant higher value in $\mathrm{HCC}$ group versus $\mathrm{HCV}$, and healthy control groups $(\mathrm{P}=0.02)$. Further we analyzed the correlation between HGF, with the laboratory findings of HCC.As shown in Table (3), in HCC there were a statistically significant positive correlation between HGF with serum ALT, SGOT, platelets, HCV copy numbers, and AFP level. Moreover, no statistical significant correlation was found among the studied HGF and the other parameters. 
Table 2.Comparison of the mean values of fold change of the studied HGF and AFP median values as markers for differentiatingHCC Group from the other Groups

\begin{tabular}{|c|c|c|c|c|}
\hline \multirow{2}{*}{ Variables } & \multicolumn{3}{|c|}{ Mean \pm SD } & \multirow{2}{*}{$\begin{array}{c}\mathbf{P} \\
\text { value }\end{array}$} \\
\hline & Control $(n=10)$ & HCV $(n=12)$ & HCC $(n=14)$ & \\
\hline Log gapdh for HGF & $(2.44 \pm 2.490)^{1}$ & $(4.50 \pm 4.237)^{2}$ & $(7.35 \pm 6.037)^{3}$ & 0.046 \\
\hline $\begin{array}{l}\text { AFP (up to } \\
\mathbf{n g} / \mathbf{m l})\end{array}$ & $(\mathbf{1 . 1 2} \pm \mathbf{1 . 3 5 5})^{1}$ & $(3.33 \pm 1.35)^{1}$ & $\left((290.21 \pm 202)^{2}\right.$ & $\begin{array}{l}\mathbf{0 . 0 2 0} \\
*\end{array}$ \\
\hline
\end{tabular}

Groups bearing different numbers are significantly different from each other at $\mathrm{P}<0.05$

* show statistical significant difference

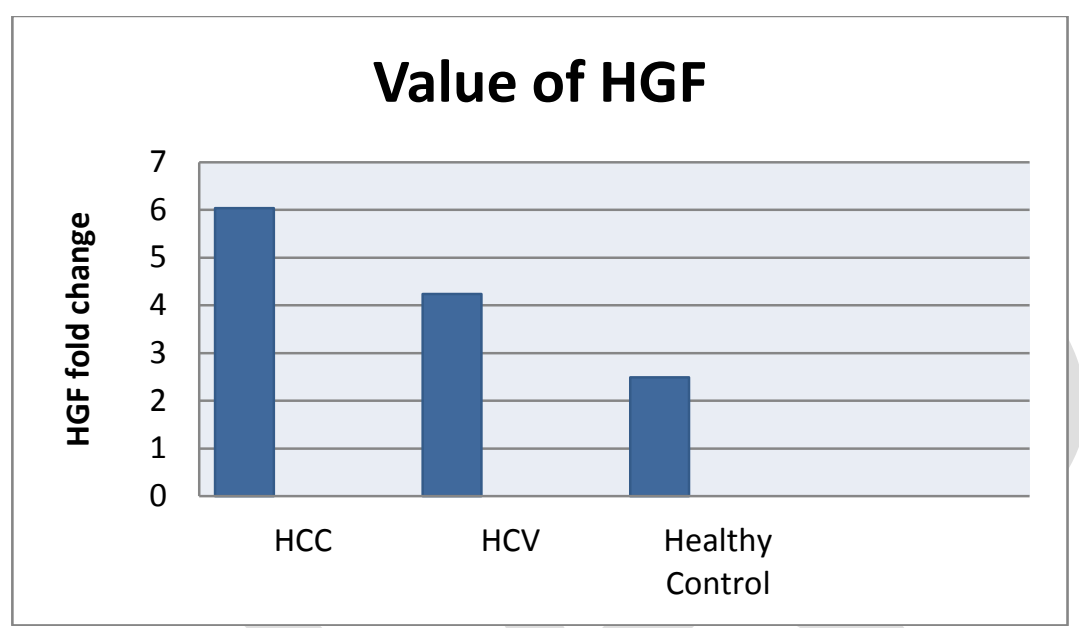

Fig (1). The value of HGF in HCC, HCV and healthy control

Table 3.Spearman correlation between HGF and laboratory parameters of HCC group.

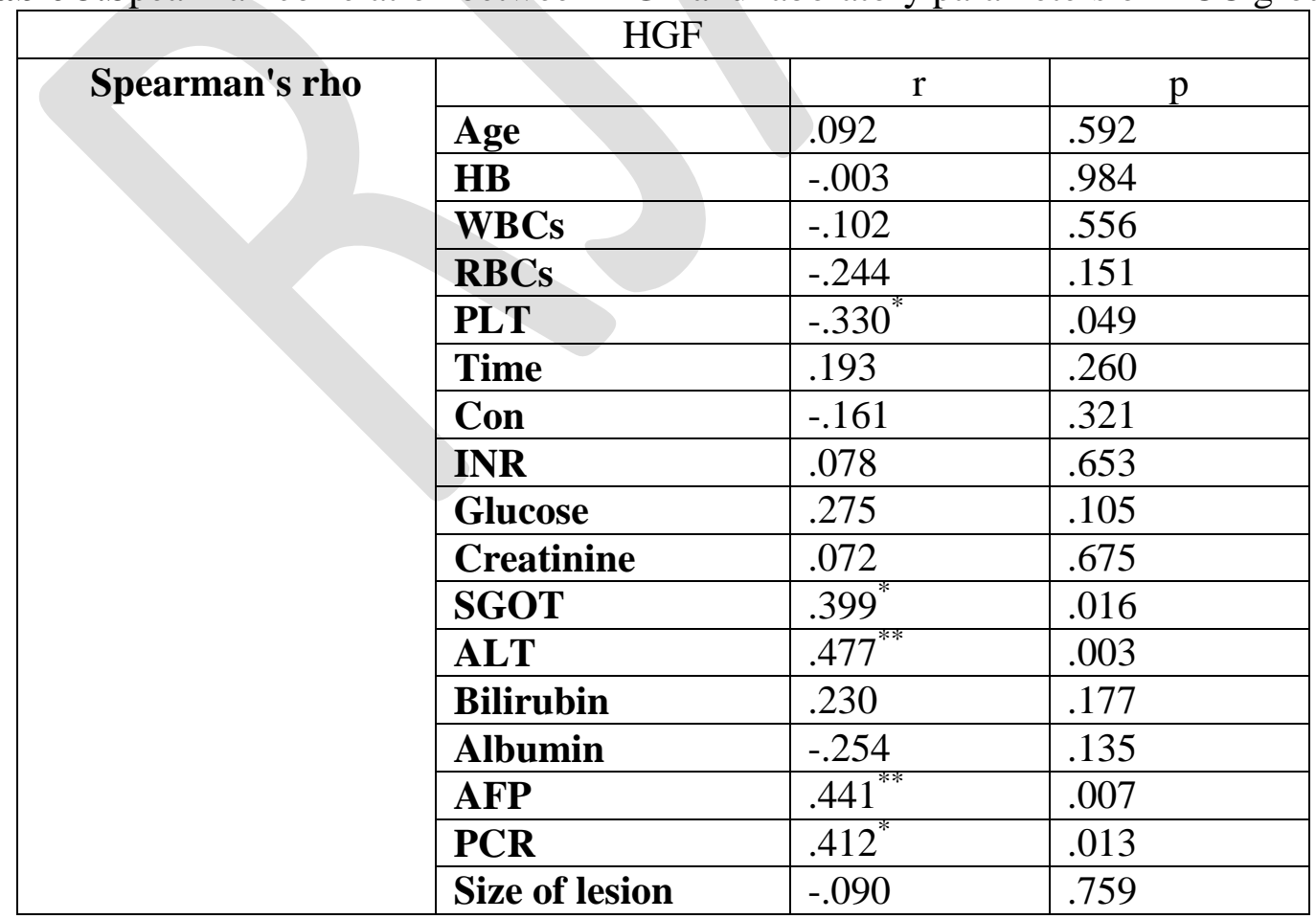


HGF as a potential tumor marker for $\mathrm{HCC}$

We used ROC curve analysis to compare the accuracy of noninvasive level of HGF and AFP to predict patients with HCC. It was found that HGF could predict HCC at level of 2.78 fold with sensitivity $85.7 \%$ and specificity $90.9 \%$ while with AFP could predict $\mathrm{HCC}$ at level of $9 \mathrm{ng} / \mathrm{dl}$ with sensitivity $75 \%$ and specificity $70 \%$

(Table 4,5 Fig 2). From these result it was clarified that the HGF is more sensitive and specific in prediction of HCC when comparing with conventional tumor marker AFP and in turn it will have a better implications on the HCC treatment outcome. Overall, these results suggest that HGF could serve as a useful tumor biomarker for prediction of $\mathrm{HCC}$ in comparing with, $\mathrm{HCV}$, and healthy control results.

Table 4 Association, agreement and validity of new cutoff regard HCC

\begin{tabular}{|c|c|c|c|c|c|c|c|c|}
\hline & \multicolumn{2}{|l|}{ Group } & \multirow{2}{*}{ Total } & \multirow[t]{2}{*}{$\mathbf{X}^{2}$} & \multirow{2}{*}{$\begin{array}{l}\text { Kappa } \\
\text { agreement }\end{array}$} & \multirow[t]{2}{*}{$\mathbf{P}$} \\
\hline & & & Not & Malignant & & & & \\
\hline \multirow[t]{4}{*}{ HGF } & \multirow[t]{2}{*}{$-\mathrm{VE}<2.78$} & Count & 20 & 2 & 22 & \multirow[t]{4}{*}{4.82} & \multirow[t]{4}{*}{0.36} & \multirow[t]{4}{*}{$0.028 *$} \\
\hline & & $\%$ & $90.9 \%$ & $14.3 \%$ & $61.1 \%$ & & & \\
\hline & \multirow[t]{2}{*}{$+\mathrm{VE}>2.78$} & Count & 2 & 12 & 14 & & & \\
\hline & & $\%$ & $9.0 \%$ & $85.7 \%$ & $38.9 \%$ & & & \\
\hline \multirow{2}{*}{\multicolumn{2}{|c|}{ Total }} & Count & 22 & 14 & 36 & & & \\
\hline & & $\%$ & $100.0 \%$ & $100.0 \%$ & $100.0 \%$ & & & \\
\hline
\end{tabular}

Sensitivity $\mathbf{8 5 . 7 \%}$

Specificity $\mathbf{9 0 . 9 \%}$

Table 5. Association, agreement and validity of AFP regard HCC

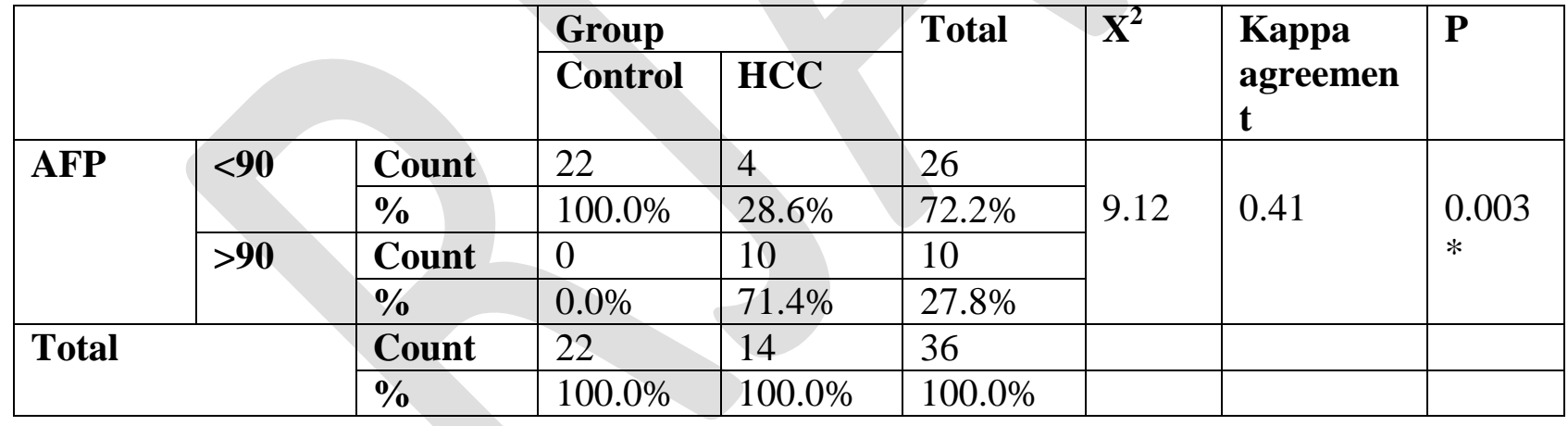

Sensitivity $\mathbf{7 5 . 0} \%$

Specificity $\mathbf{7 0 . 0 \%}$

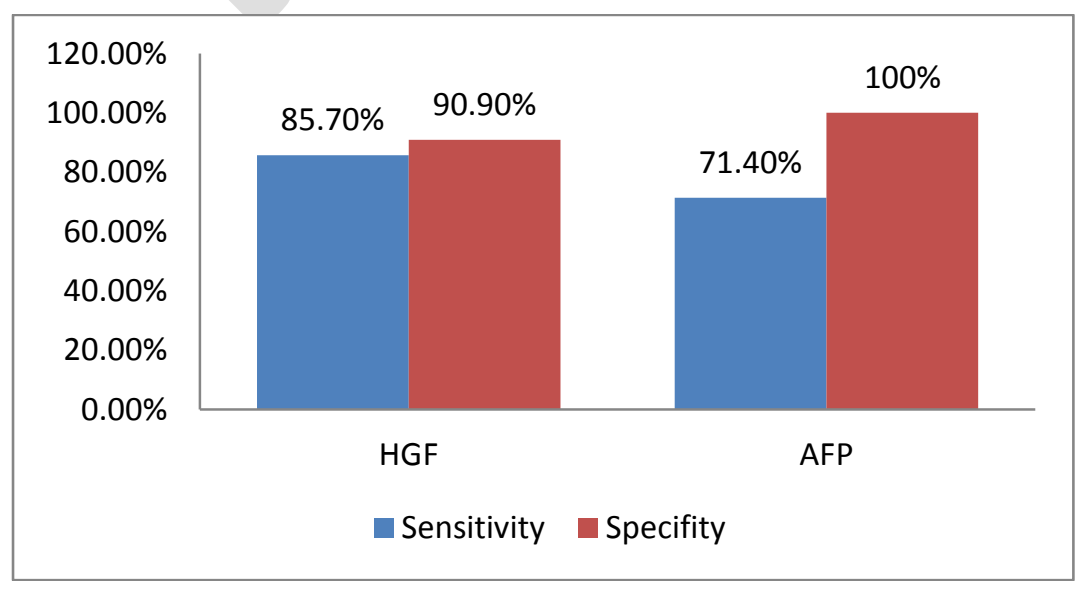

Fig 2. Comparison of HGF and AFP sensitivity and specificity for HCC predication 


\section{DISCUSSION}

HGF has been used as a prognostic marker in HCC. Serum HGF levels greater than or equal to $1.0 \mathrm{ng} / \mathrm{mL}$ have been associated with poor survival in HCC patients (Vejchapipat et al., 2004).Hepatocyte growth factor (HGF) is a hepatotrophic factor which stimulates liver regeneration. It was originally identified and cloned as a mitogenic protein for mature hepatocytes and was described as a potent stimulator of hepatocyte growth, and an important regulator of liver regeneration in response to injury (Yanagita et al., 1992). The liver is normally responsible for clearance of HGF, if this function is markedly compro-mised by liver damage (viral, toxic, anoxic, resection) the circulating HGF level rapidly increases and reaches a high level to produce potent mitogenic effect on liver cell (Sakaguchi et al., 1994). HGF is a multifunctional cytokine and has been implicated in the pathogenesis of several tumors, through increasing motility and invasiveness of cancer cells both under in vivo and in vitro conditions (Matsumoto et al., 1994).

In our study the detection rate HGF was significantly higher in patients with HCC than in patients with HCV and healthy patient $(\mathrm{P}<0.028)$.

HGF showed significant increase in HCC compared to control cases and to $\mathrm{CH}$ group. (Yoshinaga et al., 1993).

In our study the patient with HGF concentration was cutoff above 2.3 fold change, the mean HGF concentration was $4.50 \pm 4.23$ fold change in the HCV group, $2.44 \pm 2.49$ fold change in the healthy group and concentration was cutoff above 2.78 fold change, the mean HGF concentration was $7.35 \pm 6.03$ fold change in the HCC group. The main HGF level in HCC group was significantly higher than HCV group and control patient. In this study, all the patients with serum HGF concentration above 2.78 fold changewere in the HCC group. Therefore patients with $\mathrm{HCV}$ or cirrhosis may be in highly carcinogenic state when their serum HGF concentration is above 2.3 fold changes at initial examination. The level of HGF represents the degree of the carcinogenic state in the liver of patients with $\mathrm{C}$-viral $\mathrm{CH}$ and cirrhosis.

In the past decade study has demonstrated that the levels of serum HGF in patients with inoperable HCC were higher than those in healthy controls. The serum HGF level of healthy adults in this study was not different from those of other reports (Tsubouchi et al,. 1991; Shiota et al,. 1995). HGF had not been found immunohistochemically in normal liver without cirrhosis or chronic hepatitis (Yoshinaga et al., 1993).

In this study the HGF in HCC have high Sensitivity $85.7 \%$ specificity $90.9 \%$ than in HCV group Sensitivity $75.0 \%$ Specificity $70.0 \%$ but when compare the HGF with AFP in HCC group the HGF is high Sensitivity $85.7 \%$ than AFP Sensitivity $71.4 \%$ but AFP negative show in $\mathrm{HCV}$ patient while HGF in HCV were high specificity by $70.0 \%$ and sensitivity by $75.0 \%$. At these study show, the HGF concentration were elevated in the patient with high level of AFP and when low AFP level, had HCC even if their AFP levels remained with the normal range suggesting that HGF may be a tumor marker of HCC occurrence. It is high significant correlation between HGF and AFP to all patient HCC group ( $\mathrm{r}=0.441, \mathrm{P}=0.007)$. In our study, even patients with normal AFP levels had high HGF levels.

Furthermore, only one third of patients with HCC have AFP levels higher than $\quad 100 \mathrm{ng} / \mathrm{ml} \quad$ (Torzilli et al.1999; Ebara et al. 1989).

Our study showed correlations rate of HGF in the patient group with platelete counts less than $130,000 / \mathrm{mm}^{3}$ was significantly higher than that in the other group, have correlation between HGF in HCC and Platelet count ( $r=-0.330, p=0.049)$ are also significant risk factor.

The detection rate of HGF in the patient group with platelet count less than $100,000 / \mathrm{mm}^{3}$ was significant higer than that 
in the other groups (Yamagamim et al., 2002).

Serum HGF levels were significantly higher in the patients with elevated serum alanine aminotransferase ALT levels than others with normal serum ALT levels ( $\mathrm{p}<$ 0.0001 ), and have correlation between HGF and elevate ALT in HCC patient $(r=0.477$, $\mathrm{p}=0.003$ ) and significantly high in the patient with elevated serum aspirate aminotransferase AST level than others with normal serum AST levels in HCC patient $(\mathrm{r}=0.399, \mathrm{p}=0.016)$, Parallel to our results, (Sami et al., 2003).

In our study, we found a positive significant correlation between HGF and AFP for all the participants studied $(\mathrm{r}=$ $0.441, \mathrm{P}=0.007$ ); however, we did find this correlation in each group separately. The same results were reported by (Yamagamim et al., 2002).

\section{Conclusion}

In the present there was high significant increase of HGF in HCC and $\mathrm{HCV}$ than healthy control. HGF useful for detect $\mathrm{HCC}$ and have high sensitivitythan AFP. Finally the HGF could be used as a potential marker for HCC patients.

Recommended, required more additional studies to investigate with high sample size to determine molecular evaluation of these markers in HCC.

\section{REFERENCES}

Belghiti, J. and Fuks, D. (2012): Liver resection and transplantation in hepatocellular carcinoma. Liver Cancer 1: 71-82.

Bukh, J.; Miller, R. and Purcell, R. (1995). Genetic heterogeneity of hepatitis C virus: quasispecies and genotypes. Semin Liver Dis 15: 41-63 [PMID: 7597443 DOI: 10.1055/s-2007-1007262].

Ebara, M. Ohto M. and Kondo, F. (1989). Strategy for early diagnosis of hepatocellular carcinoma (HCC). Annals of the Academy of Medicine, Singapore, 18: 83-89.

Fattovich, G.; Stroffolini, T.; Zagni, I. (2004).Hepatocellular carcinoma in cirrhosis: incidence and risk factors. Gastroenterology 127:S35-50.

Ferlay, J.; Shin, H.; Bary, F. et al (2010).Estimates of Worldwide burden of cancer in

2008: GLOBCAN 2008. Int J cancer. 127:2893-917

Guirouilh, J.; Le Bail, B.; Boussarie, L. et al (2001). Expression of hepatocyte growth factor in human hepatocellular carcinoma. J Hepatol. Jan;34(1):78-83. PMID 11211911.

Hoofnagle, J. (2002). Course and outcome of hepatitis C. Hepatology 36S21S29.

Kishi, Y.; Hasegawa, K.; Sugawara, Y. et al (2011). Hepatocellular carcino-ma: Current management and future development-improved outcomes with surgical resection.Int J Hepatol 2011: 728103.

Kobayashi, K.; Sugimoto, T.; Makino, H. et al (1985). Screening methods for early detection of hepatocellular carcinoma. Hepatology 5: 1100-1105.

Matsumoto, K.; Tajima, H.; Hamanoue, H. et al.,(1994): Identi-fication and

characterization of injuring an inducers of expression of the gene for hepatocyte growth factor. Proc. Natl. Acad .Sci. USA: 89: 3800.

Moradpour, D. and Penin, F. (2013). Hepatitis C virus proteins: From structure to function.Curr.Top.Microbiol.Immunol. 369, 113-142.

Nakamura, T. (1991).Structure and function of hepatocyte growth factor.Prog Growth Factor

Res 3:67-86.

Nakamura, T. (1994).Hepatocyte growth factor as mitogen, motogen and morphogen and its roles in organ regeneration. Princess Takamatsu Symp. 24:195-213

Neaud, V.; Faouzi, S.; Guirouilh, J. et al (1997).Human hepaticmyofibroblastsincrease invasiveness of hepatocellular carcinoma cells: evidence for a role of hepatocyte growth factor. 
Hepatology. Dec;26(6):1458-66. PMID 9397985.

Neumann, A. (1998). Hepatitis C viral dynamics in vivo and the antiviral efficacy of interferon-alpha therapy. Science, 282(5386): 103-7.

Niepmann, M. (2013).Hepatitis C virus RNAtranslation.Curr.Top.Microbiol.Immunol.369,143-166.

Noguchi, O.; Enomoto, N.; Ikeda, T. et al (1996).Gene expressions of c-met and hepatocyte growth factor in chronic liver disease and hepato-cellular carcinoma. J Hepatol. Mar;24(3):286-92. PMID 8778194.

Palmer, D. (2008). Sorafenib in advanced hepatocellular carcinoma. N Engl J Med 359: 2498, author reply 2498-2499.

Paul, S.; Gulati, M.; Sreenivas, V. et al (2007). Evaluating patients with cirrhosis for hepatocellular carcinoma: value of clinical symptomatology, imaging and alpha-fetoprotein. Oncology 72(Suppl. 1): 117-123.

Perz, J.; Armstrong, G.; Farrington, L. et al (2006). The contributions of hepatitis $\mathrm{B}$ virus and hepatitis $\mathrm{C}$ virus infections to cirrhosis and primary liver cancer worldwide. J Hepatol. 45:529-38.

Sakaguchi, H.; Seki, S.; Tusubouchi, H. (1994). Ultra-structure location of human hepatocyte growth factor in human liver. Hepatology 19:1157.

Sami, A.; Abd-Elfattah, Mohsen, M. et al., (2003). Expression of hepatocyte growth factor receptors in chronic liver diseases. The Egyptian Journal of Gastroenterology.8.(1): 179.

Selden, C.; Farnaud, S.; Ding, S. et al (1994).Expression of hepatocyte growth factor mRNA, and c-met mRNA (hepatocyte growth factor receptor) in human liver tumours. J Hepatol. Aug;21(2):227-34. PMID 7989714

Shiota, A.; Okano, J.; Kawasaki, H. et al (1995). Serum hepatocyte growth factor levels in liver diseases: clinicalimplications. Hepatology 21:10612.
Simmonds, P. (2013). The origin of hepatitis $\mathrm{C}$ virus.Curr Top MicrobiolImmunol. 369: 1-15 [PMID: 23463195 DOI: 10.1007/978-3-642-273407_1.3 genome.

Simmonds, P.; Becher, P.; Collett, MS. et al (2011).Flaviviridae. In: King AMQ, Adams MJ, Carstens EB, Lefkowitz EJ (eds) Virus taxon-omy. Elsevier, Oxford, pp 1003-1020.

Singal, A.; Volk, M.; Waljee, A. et al (2009). Meta-analysis: surveillance with ultrasound for early-stage hepatocellular carcinoma in patients with cirrhosis. Aliment PharmacolTher 30: 3747.

Seol, D.; Chen, Q. and Zarnegar, R. (2000).Transcriptional activation of thehepatocyte growth factor receptor (cmet) gene by its ligand (hepatocyte growth factor) is mediated through AP-1. Oncogene. Feb 24;19(9):1132-7. PMID 10713700.

Torzilli, G.; Minagawa, M.; Takayama, T. et al (1999). Accurate preoperative evaluation of liver mass lesions without fine-needle biopsy. Hepatology 30: 889-893

Tsubouchi, H.; Niitani, Y.; Hirono, S. et al (1991). Levels of the human hepatocyte growth factor in serum of patients with various liver diseases determined by an enzyme-linked immunosorbent assay. Hepatology 13:1-5.

Ueno, M.; Uchiyama, K.; Ozawa, S. (2011). Adjuvant chemolipiodoli-zation reduces early recurrence derived from intrahepatic

metastasis of hepatocellular carcinoma after hepatectomy. Ann SurgOncol 18: 3624-3631.

Vejchapipat, P.; Tangkijvanich, P.; Theamboonlers, A. et al (2004). Association between serum hepatocyte growth factor and survival in untreated hepatocellular carcinoma. J Gastroenterol. Dec;39(12):1182-8. PMID 15622483

Yamagamim, H.; Moriyama, M. Matsum-ura, H. et al (2002). Serum 
concen-trations of human hepatocyte growth factor is a useful indicator for predicting the occurrence of hepatocellular carcinomas in C-viral chronic liver diseases. Cancer. Aug 15;95(4):824-34. PMID 12209727.

Yanagita, K.; Nagaike, M.; Ishibashi, H. et al (1992). Lung may have an endocrinefunction producing hepatocyte growth factor in response to injury of distal organs. BiochemBiophys Res Commun. Jan 31;182(2):802-9. PMID 1531175.

Yoshinaga, Y.; Matsuno, Y.; Fujita, S. et al (1993).Immunohistochemical detectionof hepatocyte growth factor/scatter factor in human cancerous and inflammatory lesions of various organs. Jpn J Cancer Res 84:1150-1158 